\title{
Case study: the contributions of a FabLab to a Bachelor cursus in Occupational Therapy
}

\author{
Jérôme Mizeret ${ }^{1, *}$, Nathalie Nyffeler ${ }^{2}$, Sylvie Ray-Kaeser ${ }^{3}$, Noémie Délèze ${ }^{2}$, and Mélanie \\ Thomas $^{1}$ \\ ${ }^{1}$ Haute École Arc, HES-SO University of Applied Sciences and Arts Western Switzerland \\ ${ }^{2}$ Haute école d'ingénierie et de gestion du canton de Vaud, HES-SO University of Applied Sciences \\ and Arts Western Switzerland \\ ${ }^{3}$ Haute École de Travail Social et de la Santé, HES-SO University of Applied Sciences and Arts \\ Western Switzerland
}

\begin{abstract}
The aim of this research is to explore the contributions of FabLabs in applied tertiary education (Bachelor University of Applied Sciences - UAS), and particularly in the form of hybrid teaching modules, combining academic subjects and maker experience. FabLabs can offer services to the professors of various academic fields to reinvent their teaching methodologies, incorporating making as a way to transmit knowledge and enhance student engagement. We have also established with higher education professors and lecturers in mind, the conditions for the implementation of such modules in order to guarantee their success. A pilot project has been conducted with occupational therapy students consisting of a one-semester module of 30 periods, dedicated to developing and prototyping in order to adapt toys and games to be used by children with cerebral palsy of the spastic hemiplegia type. The FabLab was the place where prototypes were made, but also where exchange, collaboration and creativity were catalysed. Our observations showed that the students developed three types of skills: technical (use of digital 3D CAD software and machines), occupational, in the field of occupational therapy (observation and analysis of the accessibility of the environment, solutionoriented approach aimed at increasing occupational performance and participation) and relational (creativity, agility, collaboration). Commitment and pleasure of learning were present throughout the module. The conditions for the success were the co-construction of the learning experience by both the professors and the labmanagers in charge of the FabLab, the establishment of a pedagogical scenario, and constant, open communication between them.
\end{abstract}

\section{Introduction}

In the context of a fast evolution of teaching methods, we propose to explore a promising field of pedagogical innovation that is currently opening up: the creation of conditions favourable to the emergence of competences for students at Bachelor or Master level,

\footnotetext{
*Corresponding author: jerome.mizeret@he-arc.ch
} 
thanks to collaborative and open places such as FabLabs or makerspaces, and through a project-based learning (PBL) approach. FabLabs (contraction of Fabrication Laboratory) are places open to the public that provide digital tools and machines (3D printer, laser cutter, electronic components, etc.) for the designing and making of artefacts and prototypes. They attract designers, architects, engineers and artists as well as students, citizens and companies. They are thus places for meeting and collaborating on various projects, promoting the exchange of experience and skills between users, while benefiting from the support of a lab manager.

This work is part of a research project in Pedagogical Innovation funded by the University of Applied Sciences of Western Switzerland (HES-SO), which aims to explore the use of third places as pedagogical services and their role in the development of skills. In the course of this study during the year 2019, three pilot projects were carried out with different student populations. This article reports on one of these projects, which took place at the Haute École Arc (HE-Arc) and more precisely in its FabLab, with occupational therapy students from the Haute École de Travail Social et de la Santé de Lausanne (HETSL), both of which are part of the HES-SO. We are therefore in a cross-domain context, which adds complexity but also opens the benefits to a larger audience.

Our approach is both very promising and delicate to implement, as it must combine two aspects that are difficult to reconcile. On the one hand, the aim is to give a central role to students, allowing them a great deal of autonomy of action, exploration, experimentation and collaboration. This is the typical mode of action of makers (term defined below). On the other hand, in tertiary education and especially in UAS that have a strong vocational component, professors/lecturers should be able to ensure that the requirements in terms of learning outcomes are met and assessed [1-3]. These two rather opposite constraints can create significant tensions in terms of the nature and intensity of supervision [4]. Understanding the conditions under which a maker-based teaching module is delivered is therefore important.

The first section of this paper will present the background, i.e. previous work by various authors in the domain, starting with a strong statement by Dale Dougherty, the founder of the journal Make, a ubiquitous reference publication for makers. The two following sections (3 and 4) describe the concept we want to implement, a hybrid module combining an academic Bachelor course with a practical maker experience in a FabLab, and our approach to do so. The practical part includes the observations made (section 5), the discussion around these observations (section 6), and finally a conclusion (section 7).

\section{Background}

The contribution of FabLabs and makerspaces is studied in the literature particularly for primary and secondary education, see for example [5], but also for tertiary education. In various papers, Dale Dougherty presents a major aspect of the dynamic that FabLabs and makerspaces help to create, which he calls the maker mindset [6]. As he puts it, this mindset is characterised by the fact that makers "play with technology to learn about it. A new technology presented an invitation to play, and makers regard this kind of play as highly satisfying. Makers give it a try; they take things apart; and they try to do things that even the manufacturer did not think of doing". This is known as hacking, in the original sense of diverting an object from its original use. "Like artists, makers are motivated by internal goals, not extrinsic rewards. They are inspired by the work of others. Most importantly, they do not wait until the future to create and make. They feel an urgency to do something now - or lose the opportunity to do it at all". Dougherty then adds "We can create a workshop or makerspace, and we can acquire tools and materials, but we will not 
have succeeded at creating innovative thinkers and doers unless we are able to foster a maker mindset".

The objective of offering maker modules is therefore to create the conditions of emergence of this state of mind and the personal and relational skills (soft skills) that come with it. They include: creativity and the ability to work in a problem-solving mode, agility, collaborative spirit and exchange of information, interdisciplinarity and a systemic approach, autonomy, co-construction and co-learning, commitment and the pleasure to learn $[1,3,7-10]$. The importance of these skills is growing in the era of digitalisation and thus of the automation of many jobs [11-13].

It should also be noted that this maker mindset is naturally present in individuals at varying degrees. To be successful, the training module should therefore adopt design strategies that allow as many students as possible, regardless of their predisposition, to benefit from them. Different levels of skills must therefore be able to coexist in a maker module, which can suit both the most agile and the non-experts [4, 14].

\section{Concept}

We have identified three possible approaches. In the first configuration, the maker module is offered per se, i.e. the participants will have training on the different equipment and a maker experience, without any other pedagogical purpose. For example, the Hogeschool Rotterdam (Rotterdam University of Applied Science) offers block course modules of different durations (from one day to several weeks) to their students, whatever their curriculum. They enrol to discover digital fabrication (laser cutter, 3D printer, vinyl cutter, etc.) and the programming of electronic components based on Arduino or microbits [15, 16]. In another case, the universities of Cergy-Pontoise and of Belfort-Montbéliard (UTBM) offer training courses to become FabLab managers [17]. In these cases, the use of the FabLab is both the means and the end [18].

Regarding the other two approaches, those we have chosen to explore, the assumption is that the pedagogical contribution of FabLabs is increased when the experience is linked to a specific academic course that is part of the cursus and contributes to the profile of competences. This requires a careful articulation between the maker world and the subject taught, which can be established either when the professors/lecturers are makers themselves - this approach was implemented in another pilot project also part of this research (and as well as in Rotterdam where the modules described above are open to the teaching and administrative staff); or by a close collaboration between the professors/lecturers and the lab managers so as to supervise the students together (case reported here).

Combining an academic subject to the maker module, and thus turning it into a hybrid module, allows for three types of skills to emerge simultaneously. Firstly, the personal and relational skills, as described above. Secondly, the technical skills linked to the appropriation of the manufacturing and prototyping technologies found in FabLabs (3D CAD modelling and printing, electronics, sensors, etc.). These are specific technical skills, but their scope and importance increase with the evolution of technologies. In particular, 3D CAD modelling, previously accessible mostly to design engineers or designers, can now be seen as a new form of digital literacy, likely to be used by, and within reach of, the largest number of people. Thirdly, the professional skills linked to the specific course subject and activated during the project. In the case of this study, it was to design a toy or game adaptation for children with disabilities (occupational therapist profile), but in other cases it may be to develop skills in architecture [8], medicine [7], engineering [19], design $[3,15,20,21]$, an artistic branch or even a writing workshop [1]

Our research objectives are therefore as follows. Firstly, being an exploratory project, our intention is to observe and map the functioning of a hybrid module as described above, 
in the specific case of non-engineering students. Secondly, we wish to understand the conditions for the success of such a module, in particular with regard to the relationship between the professor's field of action (academic subject) and the FabLab.

\section{Approach}

This article relates the experience of an elective course, offered during the third and final year of the Bachelor's degree in occupational therapy, with the objective of 1) adapting toys and games for children with cerebral palsy (CP) of the spastic hemiplegia type; 2) modify toys and games to improve its accessibility for any child based on Universal Design principles, and therefore enabling students to develop specific skills for the future practice of their profession.

The students had previously acquired theoretical knowledge about the assessment of children with CP according to the MACS manual ability classification system [22], of play objects with the TUET toys and games usability evaluation tool [23] and how to help them in everyday tasks, which includes the adaptations of objects. The theory is therefore in principle already known and will be put into practice. The course consists of 30 teaching periods and 30 hours of independent work, for a total of 2 ECTS.

The teaching covers the discovery of 3D CAD modelling and printing, a section of the innovation approach known as Design Thinking [24], and finally a challenge to be undertaken (design, prototyping, evaluation and presentation). A part of the module is given at the HETSL premises by the labmanager and the other at the HE-Arc FabLab in Neuchâtel.

The course unit has been evaluated for the purposes of the research, and in order to be able to reproduce it in other situations / areas and to make it evolve. Several types of information were collected from different audiences at different stages of the project. At the beginning of the module, an interview was conducted with the HETSL professor, and a "pre-workshop" online survey was sent to students (100\% response rate). During the workshops at the FabLab, ethnographic-type observations were carried out. At the end of the module, an online "post-workshop" student survey ( $91 \%$ response rate) and an interview with the HETSL Professor were conducted again. In addition, a large amount of information was collected by the various stakeholders throughout the process, apart from the systematic actions described above.

The program of the course unit is presented in Table 1. A first session (stage 1) presents the objectives, the programme, the practical organisation, the project objective and the toy or game to modify according to the manual abilities of a child with $\mathrm{CP}$. The project groups were formed: eight female and three male students enrolled and were placed into three project groups of three to four people. Each group was given a different toy or game to adapt for the same child. In this way, the groups are not in competition, but could rather support and help each other.

The work began with an ideation phase (stage 2), i.e. creativity and thinking on the proposed problem, in project groups. This work preceded the visit to the FabLab, so as not to bias the ideation work. Indeed, it would be counterproductive to let the technology influence or restrict the creative vocational work. The fictitious patient must remain the focus of the thought process at this stage. The work in this phase is autonomous (in groups), but tutor sessions have been arranged and used by the students. 
Table 1. Module description (in italics the autonomous work).

\begin{tabular}{|c|c|c|}
\hline Stage & Time and place & People involved \\
\hline $\begin{array}{l}\text { 1. Introductory session: presentation of the } \\
\text { programme and organisation }\end{array}$ & $\begin{array}{l}2 \text { periods } \\
\text { HETSL }\end{array}$ & $\begin{array}{l}\text { Professors from } \\
\text { HETSL and HE- } \\
\text { Arc }\end{array}$ \\
\hline $\begin{array}{c}\text { 2. Ideation phase: Reflection on the problem and } \\
\text { development of ideas } \\
\text { Tutor session }\end{array}$ & 4 periods & $\begin{array}{l}\text { Autonomous } \\
\text { HETSL professor }\end{array}$ \\
\hline $\begin{array}{l}\text { 3. Visit to the FabLab: training on the machines and } \\
\text { introduction to Design Thinking }\end{array}$ & $\begin{array}{c}4 \text { periods } \\
\text { FabLab HE-Arc }\end{array}$ & $\begin{array}{l}\text { Labmanager, } \\
\text { Lecturer Design } \\
\text { Thinking }\end{array}$ \\
\hline $\begin{array}{l}\text { 4. 3D modelling training } \\
\text { Design and development }\end{array}$ & $\begin{array}{l}8 \text { periods - } \\
\text { HETSL } \\
14 \text { periods }\end{array}$ & $\begin{array}{l}\text { Labmanager } \\
\text { Autonomous }\end{array}$ \\
\hline 5. Prototyping FabLab 1 & $\begin{array}{l}4 \text { periods } \\
\text { FabLab HE-Arc } \\
2 \text { periods }\end{array}$ & $\begin{array}{l}\text { Labmanager } \\
\text { Autonomous }\end{array}$ \\
\hline 6. First report - formative evaluation & $\begin{array}{l}2 \text { periods } \\
\text { HETSL }\end{array}$ & $\begin{array}{l}\text { Professors from } \\
\text { HETSL and HE- } \\
\text { Arc }\end{array}$ \\
\hline $\begin{array}{c}\text { 7. Second cycle: modelling and prototyping } \\
\text { (adaptation / modification of the initial prototypes) } \\
\text { Design and development }\end{array}$ & $\begin{array}{c}8 \text { periods } \\
\text { FabLab HE-Arc } \\
10 \text { periods }\end{array}$ & $\begin{array}{l}\text { Labmanager } \\
\text { Autonomous }\end{array}$ \\
\hline 8. Second report - graded & $\begin{array}{l}2 \text { periods } \\
\text { HETSL }\end{array}$ & $\begin{array}{c}\text { Professors from } \\
\text { HETSL and HE- } \\
\text { Arc }\end{array}$ \\
\hline
\end{tabular}

Then there was a first visit to the FabLab (stage 3), not to build prototypes, which would be premature at this time of the process, but to discover the place and receive training on the two main machines intended to be used at a later stage (laser cutter and 3D printer) as well as on the proposed Design Thinking methodology. The idea behind discovering these tools is to open up minds, enhance creativity, and become aware of new possibilities for making and prototyping.

Next, a two four-period training session on a 3D CAD modelling tool followed (step 4). Mastering such a digital tool is essential for the prototyping phase that follows, and will also be an asset throughout the future professional life of the students. During this period of time, the autonomous ideation and design work continues.

The first making workshop at the FabLab follows (step 5), during which the groups produce mock-ups (loose prototypes) of their design ideas or even a working prototype. This artefact is then presented in front of the professors and labmanager (step 6). This evaluation is essentially formative and closes a complete design cycle. The whole class attends the presentations of all the groups, thus encouraging the transmission of information and horizontal peer-to-peer observations. Discussions are held to determine which directions to orientate the work.

A second cycle follows (steps 7 and 8), during which the design cycle is run through a second time (ideation, design, prototype, evaluation) with a slightly modified challenge. Starting with the same toys and games, the aim is this time not to adapt the objects in a oneoff way for an identified child, but to propose modifications to the manufacturer so as to meet the requirements of universal design from the outset and so that the toys and games can be used by any child, with or without disability. This was followed by four more periods of $3 \mathrm{D}$ CAD modelling training and workshops in parallel with independent 
ideation/design work. Finally, a second workshop in the FabLab was proposed to make a more complete functional prototype, which was then presented to the same audience as in step 6, this time graded.

\section{Observations}

At enrolment, the students had little knowledge/awareness of FabLabs. At most, some had heard of them ( 3 out of 11), but none had ever entered one or used the machines there. The perception of what a FabLab is was nevertheless generally correct (a place where equipment and tools are made available / which encourages innovation in a collaborative mode / where you meet people of all profiles who come to carry out a project), although there were biases concerning the belief that they had only $3 \mathrm{D}$ printers to the exclusion of other digital manufacturing machines, and that one can have parts made there (subcontractor mode). Nevertheless, it should be noted that almost everyone had already made an object by themselves, either in autonomous mode or according to a procedure.

The observations made during the workshops in the FabLab showed that the autonomy of action increased throughout the module. At the beginning, the information was essentially transmitted vertically top-down from the labmanager to the students. However, this gradually became more and more horizontal over the course of the semester (mutual aid, questions, exchanges, including from one group to another). This empowerment is an evidence of the acquisition of knowledge and its incorporation. The very first experience in a FabLab is always difficult for the students, as they are confronted with a large number of new aspects (environment, machines, material, makers) in a short time. From the second day onwards, however, the students start leaving the "novice" level, take initiative and even go so far as to inform other groups about this or that point which they have mastered. Curiosity towards new materials, techniques and methods is also growing.

One group spontaneously made partial prototypes to test a hypothesis, which is an approach taught in prototyping courses and is good practice, while another group "pivoted", i.e. completely reoriented their thinking, on the advice of the professors, following the fact that the proposed solution turned out to be impractical at the time of the first presentation. This demonstrates that the students have assimilated the role of prototyping in a design process.

Throughout the unit, there was a high level of commitment from all students (no dropouts or absences despite the travel time). One student also made a personal object in addition to the required work, taking advantage of the equipment available.

At the end of the module (second report, graded), we see that the complex technical tools (3D modelling, 3D printing, 2D modelling, laser cutter) are acquired at an intermediate level, i.e. the students know the principles, the operating modes and the main technical aspects. They are of course not at the level of engineer or design students, for whom these elements constitute the basis of their cursus. Nevertheless, those who want to continue to train in this direction can do so on their own (software) or by attending a FabLab or a makerspace. They have acquired enough skills to be autonomous and to further develop their art of using these tools. Those who feel less comfortable or who do not want to go further on their own have acquired knowledge to interact effectively with a professional in the field (e.g. design engineer) and to draw up specifications, communicate their needs and validate a development. The methodological tool (Design Thinking) is acquired at the beginner level. The rudiments of this practice may not make them autonomous, but nevertheless allow them to understand the process and to work effectively with professionals in the use of these tools if the situation arises in their future career.

The vocational skills in adapting objects for people with disabilities (Figure 1) were employed, self-assessed by the students, and then graded by the institution. The two 
reporting sessions allowed not only for a formative evaluation (first report) and a summative evaluation (second report), but also for group discussions with feedback from peers (professors and colleagues). The evaluation criteria focused in particular on the organisation and management of the group work, the understanding and application of 3D $\mathrm{CAD}$ modelling principles, and the interest and relevance of the toy or game adaptation.
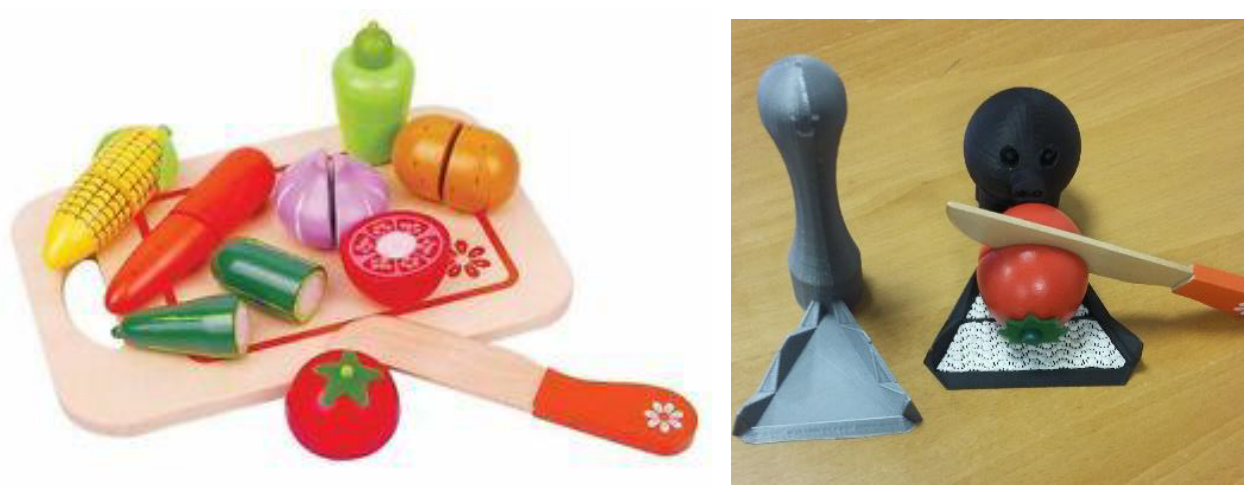

Fig. 1. Example of a toy adaptation: vegetable holding tool to facilitate cutting. On the left picture, the original toy is displayed. On the right picture, we see the modification proposed, in the form of a handle and a positioning pad that hold the fruit to cut. The left object in the right picture is the result of the first iteration; after the formative evaluation, the student embarked into a second design iteration, which lead to the object on the right.

\section{Discussion}

The skills of teamwork and creativity in groups were validated beyond what had been imagined: the collaboration went beyond the group structure, with cross-help between the three groups. A comment from the post-course survey states: "overall I enjoyed this module immensely, collaboration with students from another profession would be even more rewarding (e.g. physio, engineer, designer, etc.)". The notions of commitment and curiosity were clearly present, as shown by the comments on the aspects that were particularly appreciated: "The fact of being free in the 3D modelling of our prototype and to print what we wanted / The creativity and the concrete realisation of an idea / Discovering new resources and reference persons / The innovative aspect". Several students commented on their experience at the end of the project, mentioning that they were happy to have learned about the existence of the FabLab Neuchâtel and of the network of FabLabs in western Switzerland. They now plan to use them in their future professional activities.

Engagement and level of commitment was at a high level, as shown by the very fact that students started to teach each other. It is a clear sign that they reached a certain level of expertise. One instructive comment from the post-course survey sums up the concept of this pilot project. This person appreciated "the fact that they were developing knowledge that remained in the field of occupational therapy, but which was not "full theory" like most modules. Here we go off the beaten track, we are interested in the world of today and we acquire knowledge that is right up-to-date. This module gave me the impression that I was part of today's society and that I wasn't always stuck in our theoretical courses [...]".

This teaching unit also taught us that the collaboration between the professors/lecturers and the labmanagers is very important. The FabLab should not be seen as an entity to subcontract parts of the course. On the contrary, it must be integrated into the course in a 
very subtle way so that it forms a whole. In this pilot project, this aspect worked well and was a guarantee of success.

The time available was sufficient to experience the process, although a third workshop in the FabLab would have been ideal, as the student survey showed. Seven out of ten respondents expressed the wish to have a third session at the FabLab to further improve on some points, and one out of ten would have liked to have had more time during the prototyping sessions.

The principle of following the design cycle (divergent process aiming at imagining the maximum of solutions in brainstorming mode, followed by a convergent phase of making and prototyping) twice was essential, as we found that after one cycle only the concept of iteration is not yet assimilated, but rather understood as a linear process with no possibility of going back. Furthermore, not all of the FabLab potential is perceived and apprehended during the first cycle. For instance, the idea of using partial prototypes for validating certain hypotheses before the production of a complete proof-of-concept prototype was not yet acquired. The second cycle helps to establish these skills and gives students more confidence in their agile capacities as innovators. This is exemplified by the two objects shown in the right picture of Figure 1. The left object in the right picture was produced during the first iteration: all the elements are present, but the design and ergonomics are not optimal, as shown when tested during the formative evaluation: risk of tilting, weakness at the connection between the handle and the plate, slippery plate, etc. The second prototype on the right of the right picture, however, done during the second iteration is more complete and functional. It also includes humorous features such as the eyes and mouth to make it look more attractive for children, with or without cerebral palsy (CP); this can be seen as a sign of confidence of the designing team.

The collaboration between the professor and the labmanager is crucial to establishing a good pedagogic scenario. It is of course time-consuming and depends mostly on the agility of both and on the willingness of the professor to alter its relationship with the students to a more horizontal supervision. Under these conditions, and if done at the design level of a new course, the preparation time for the professor is not significantly different from that of a standard course design. In the case of an existing course, this of course imply a redesign and therefore an added preparation time for the first occurrence.

\section{Conclusion}

This project has addressed the two research objectives mentioned in the introduction, thanks to the observations made during a complete teaching unit of 2 ECTS, developed between two HES-SO universities for occupational therapy students at Bachelor level.

Firstly, the observations validate the interest of offering hybrid maker modules to nonengineer students. The specific degree of skill acquisition cannot be fully assessed in an exploratory study, but we were able to observe the typical traits of the maker mindset in the three fields mentioned. In terms of soft skills, we observed intra- and inter-group collaboration, enthusiasm and personal commitment, entrepreneurial mode, creativity and lateral thinking. On the level of technical skills, we observed an increasing empowerment around the use of digital manufacturing machines, the acquisition of relatively complex IT tools (3D CAD modelling, vector drawing) and the positive experience of an innovation methodology. Finally, in terms of occupational therapy skills, students were able to apply a solution-oriented approach aimed at increasing occupational performance and participation.

Secondly, we have learned that the successful operation of a hybrid course-maker module depends above all on the effective collaboration between the professors and the lab managers, and on the trust developed between them. The FabLab and its lab managers are more than simple service providers, they actively contribute to the skills acquisition, but 
also transmit the values of the maker approach. Most of the work takes place in a third place and therefore outside the usual teaching framework. The professors/lecturers must remain involved, attentive to the progress, either by their presence on site or by tutoring hours to accompany the process, and in any case by frequent and open communication with the labmanager.

\section{References}

1. R. Kaminski Sanders, T.J. Kopcha, K.L. Neumann, K. Brynteson, C. Bishop. Technology Trends, 63, 386-396 (2019)

2. J.A. Marshall, J.R. Harron. Interdisciplinary Journal of Problem-Based Learning, 12, 2, Article 2 (2018) https://doi.org/10.7771/1541-5015.1749

3. C.-K. Teng, M.-C. Chuang, C.-C. Hsu. Universal Journal of Educational Research, 3, 10, 751-756 (2015). https://doi.org/10.13189/ujer.2015.031014

4. A. Kajamaa, K. Kumpulainen, H.-R. Olkinuora. British Journal of Educational Technology, 51, 2, 371-386 (2020). https://doi.org/10.1111/bjet.12837

5. N.R. Irie, Y.-C. Hsu, Y.-H. Technology Trends, 63, 397-407 (2019) https://doi.org/10.1007/s11528-018-0355-9

6. D. Dougherty, The Maker Mindset MIT (2013)

7. L. Albala, T. Bober, L. Koeneke_Hernadez, \& B. Ku. Universal Journal of Educational Research, 6, 1, 179-183 (2018). https://doi.org/10.13189/ujer.2018.060118

8. K. Donahue. Awakening Creative Thinking through Making (2014)

9. S. Maravilhas, J. Martins. Journal of Business Research, 94, 353-359 (2019) https://doi.org/10.1016/j.jbusres.2018.01.061

10. A. Wigner. The Maker Movement, the Promise of Higher Education, and the Future of Work (Arizona State University, 2017)

11. J. Bughin, J. Manyika, M. Chui, M. Miremadi, K. George, P. Willmott, M. Dewhurst. A Future that works: Automation, Employment, and Productivity. McKinsey (2017)

12. World Economic Forum. The Future of Jobs-Employment, Skills and Workforce Strategy for the Fourth Industrial Revolution (Global Challenge Insight Report). (World Economic Forum, 2016) http://www3.weforum.org/docs/WEF_Future_of_Jobs.pdf

13. World Economic Forum, WEF_Future_of_Jobs_2018.pdf(2018).

14. K. Dreessen, S. Schepers, S. NordiCHI '18: Proceedings of the 10th Nordic Conference on Human-Computer Interaction, $482-493$ (2018)

15. M. Mostert - van der Sar, I. Mulder, L. Remlin, P. Troxler. FabLabs in Design Education. EPDE 629-634 (2013)

16. P. Troxler, M. Mostert - van der Sar. Seven Years Of Plenty? Learning At, With, Through, From And For The Fablab At Hogeschool Rotterdam (2018) https://doi.org/10.5281/ZENODO.1413621

17. UTBM, Diplôme Fabmanager (2020, juillet 22). https://www.utbm.fr/formations/formation-continue/innovation-creativite/du-fabmanager/

18. A. Nedjar-Guerre, A. Gagnebien. Agora débats/jeunesses, 69, 1, 101 (2015) https://doi.org/10.3917/agora.069.0101 
19. E. Douglas, S. Jordan, M. Lande, A. Bumbaco. ASEE Annual Conference and Exposition Proceedings, 26, 235, 1-26 (2015) https://doi.org/10.18260/p.23574

20. K. Fleischmann. International Journal of Arts \& Sciences, 08, 06, 101-108 (2015)

21. M. Haldrup, M. Hobye, N. Padfield. CoDesign, 14, 4, 329-344 (2018) https://doi.org/10.1080/15710882.2017.1378684

22. A.C. Eliasson, L. Krumlinde Sundholm, B. Rösbald, E. Beckung, M. Arner, A.M. Öhrvall, P. Rosenbaum. Developmental Medicine and Child Neurology, 48, 549-554 (2006)

23. M. Costa, O. Périno, S. Ray-Kaeser. Toys and games Usability Evaluation Tool: TUET. AIJU. www.tuet.eu (2018)

24. T. Gamba, T. I2D - Information, données \& documents, 54, 1, 30-32 (2017) 